\title{
The impact of obesity and age on the risk of falls in elderly women
}

\author{
PATRYCJA BOBOWIK*, IDA WISZOMIRSKA* \\ Józef Piłsudski University of Physical Education in Warsaw, Faculty of Rehabilitation, Warsaw, Poland.
}

\begin{abstract}
Purpose: The aim of this study was to examine the effect of obesity and age on body balance disorders in women over 60, especially whether obesity increases the FR in older females and whether age and obesity affect the same stabilographic parameters when it comes to the FR. Methods: The study consisted of 56 inactive females aged $71.77 \pm 7.43$ (SD). They were divided into groups according to age and obesity. Results: Obesity separately affects FRI12-6, static indicators with eyes closed (OSI EC, APSI EC, MLSI EC), and age affects FRI12-6 and static indices with eyes open (OSI EO, APSI EO). After considering design factors (age and obesity), there were statistically significant differences in OSI EO $(p=0.027)$, APSI EO $(p=0.034)$, FRI12-6 $(p=0.0002)$ between obese and non-obese participants in the age groups. There were no statistical differences between non-obese old and obese-young participants $(p=0.863)$. The interaction between obesity and age in the FR in static indices and in FRI12-6 ( $p=0.73047)$ was not significant. Conclusions: Age and obesity affect the stabilographic parameters individually, but there is no interaction effect between them. The presence of only one of the above risk factors may increase the FR. Obesity affects stability, while age depends on other factors. If older people are not obese or fit, involutional changes could be reversed. The type of obesity and the location of the fat tissue should be taken into account in FR assessment.
\end{abstract}

Key words: body mass index, elderly age, geriatrics, fall risk

\section{Introduction}

It is quite evident that the ageing process involves physiological changes, which manifest in increases in body weight, muscular mass loss, or body balance disorders [9]. The Word Health Organization (WHO) predicts that, between 2015-2050, the proportion of people over 60 globally may increase to $22 \%$ [27]. Moreover, the number of obese individuals is constantly increasing. Currently, more than 300 million people around the world are obese [8]. This state of affairs is a result of economic development and changes in lifestyle [6].

The risk of falls (FR) is one of the most serious problems among people aged 65 and over [11]. Falls are a consequence of many factors: degenerative changes in the vestibular and visual systems, deterioration of motor control, reduced muscle strength, the side effects of drugs taken, changes in body posture, and environmental factors [13], [34]. All this causes damage to receptors, neuronal pathways, and centres responsible for cognitive and equivalent functions. There is an abnormal flow of information between the central and peripheral nervous system [33].

Obesity is a disease characterized by increased fatty tissue, which has a negative impact on a person's health condition in various fields of medicine [3], [21]. The simplest method of assessing obesity is to determine a person's BMI value. Obesity is associated with many geriatric syndromes and it is connected with: a reduction in physical activity and performance [13], metabolic syndromes and type 2 diabetes [2], cardiovascular diseases and hypertension [9], and postural balance disorders, that result in falls [10]. Obesity plays a major role in elderly disability and falls [14]. Obesity and excess weight do not only increase the

\footnotetext{
* Corresponding authors: Patrycja Bobowik, Ida Wiszomirska, Józef Piłsudski University of Physical Education in Warsaw, Faculty of Rehabilitation, ul. Marymoncka 34, 00-968 Warsaw, Poland. Phone: + 482283404 31, ext. 393, e-mail: patrycja.bobowik@awf.edu.pl

Received: February 5th, 2021

Accepted for publication: April 1st, 2021
} 
FR, but fear of falling also. Furthermore, obese individuals are more likely to suffer from reduced quality of life following a fall [10], [17]. They also have lower muscle mass, functional parameters, and higher risk of frailty developing [2], [4], [17].

Body balance disorders can be assessed functionally or stabilographically. Stabilographic platform allow for the measurement of body balance from a biomechanical perspective. Perraca et al. [23] conclude that Biodex Balance System (BBS) SD (USA) platform measures are reliable and may be useful for measuring FR in older people. BBS allows to determine fall risk indicators in static and dynamic environments. Among other things, they showed that FRI index had high ICC $($ ICC $=0.80)$. This platform has been used to assess balance in neurological patients [31], orthopaedic patients [25], and women with vision impairments [33].

Increasing age and weight are associated with the presence of various chronic conditions [20]. It is wellknown that the FR is still one of the most common causes of injury among obese elderly individuals, something which is rarely taken into account by medical staff [7], [19]. Furthermore, some studies show that obese older people fall almost twice as often as their lean counterparts [18]. On the other hand, a lot of studies fail to report any associations between increased weight or excessive mass and falls in the elderly [24]. There are still doubts as to the impact of obesity and age as FR factors. The aim of this study was to examine the effect of obesity and age on body balance disorders in women over 60 verte.

\section{Materials and methods}

The research received approval from the Bioethical Commission in Poland. Qualification consisted of two stages. The first stage was based on an interview conducted by a physiotherapist. Inclusion criteria were: female gender, age above 60 , good mental condition, low level of physical activity declared by participants, and a willingness to participate in a research project. The second stage involved: a cardiac interview, an examination and electrocardiography carried out by a doctor of medicine. Exclusion criteria were: bad mental condition, communication problems, medications that may cause balance disorders, various chronic diseases due to imbalance, e.g., Parkinson's disease, multiple sclerosis, labyrinth disease, advanced coronary disease, and a high risk of heart attack. The last stage took place in a laboratory at the Józef Pilsudski
University of Physical Education in Warsaw. Two participants dropped out prior to this part because of deteriorating health and sudden injury. All participants whose physical and psychological status allowed them to participate in the study gave their written consent.

All participants had their height and weight measured according to the same study protocol, carried out by one person. Body Mass Index (BMI) was calculated as weight $[\mathrm{kg}] /$ height $\left[\mathrm{m}^{2}\right]$. Participants were divided into two groups according to the BMI results. The non-obese group consisted of participants with a BMI below $30 \mathrm{~kg} / \mathrm{m}^{2}$ (normal weight, overweight). The obese group comprised participants with a BMI above $30 \mathrm{~kg} / \mathrm{m}^{2}$ (obese). The body weight classification of adults based on BMI was carried out according to WHO guidelines [30].

Three protocols were prepared on the Biodex Balance System SD (BBS) platform, from Biodex, to assess postural balance. Each of them lasted 20 seconds. BBS enables testing on a stable and unstable platform at 12 levels. The degree of instability of the platform increases from 12 to 1 (the most stable platform being level 12). A postural stability test (PST) was performed on a stationary platform with eyes open (EO) and eyes closed (EC). This enabled the researchers to determinate values of various parameters: the OSI (overall stability index), APSI (anterior-posterior stability index) and MLSI (medial-lateral stability index). High values of these indices suggested a high FR. A fall risk test was also carried out with eyes open on an unstable platform at a level from 12 to 6 . On this basis, the FRI (Fall Risk Index) parameter was determined.

Participants were divided into two groups according to age. The division was carried out in accordance with WHO guidelines [29]. The younger group was formed of participants between 60 and 74 years old, and the older one contained subjects between 75 and 90 years old.

The recorded data were analysed with the use of STATISTICA (v.13), StatSoft USA. The normality of the distribution was analysed using the Shapiro-Wilk test. Each parameter was described using descriptive statistics (means and standard deviations). In addition, Brown-Forsythe homogeneity of variance test was performed. An analysis of variance (ANOVA) was carried out and post-hoc tests (an NIR test) were performed. The correlation of the results was evaluated with the Pearson's rank correlation and an NIR test. The effects and interactions between variables were verified using the ANOVA test for main effects and factorial designs. All tests were performed at the significance level of 0.05 . 
This work was supported by the Ministry of Science and Higher Education in 2020-2022 under Research Group no. 3 at Józef Piłsudski University of Physical Education in Warsaw "Motor system diagnostics in selected dysfunctions as a basis for planning the rehabilitation process".

\section{Results}

The study consisted of 56 inactive females aged $71.77 \pm 7.43$ (SD). The characteristics of the somatic parameters of the participants can be found in Table 1.

Table 1. Participants' anthropometrics

\begin{tabular}{|l|c|c|c|}
\hline & $\min$ & $\max$ & $\operatorname{mean} \pm \mathrm{SD}$ \\
\hline Body mass $[\mathrm{kg}]$ & 48.50 & 95.10 & $70.15 \pm 11.43$ \\
\hline Body height $[\mathrm{cm}]$ & 143.00 & 170.00 & $157.44 \pm 6.67$ \\
\hline BMI & 21.16 & 42.55 & $28.34 \pm 4.70$ \\
\hline WHR & 0.699 & 1.147 & $0.861 \pm 0.085$ \\
\hline
\end{tabular}

BMI - body mass index, WHR - waist-hip ratio.
The Pearson's rank correlation was performed. There were statistically significant correlations between age and OSI EO $(r=0.370)$, APSI EO $(r=$ $0.392)$, and FRI12-6 $(r=0.389)$. Statistically significant correlations was also found between BMI and OSI EC $(r=0.392)$, APSI EC $(r=0.312)$, and FRI12-6 $(r=0.455)$.

Participants were divided into two groups according to their BMI values. There were no differences between groups in the test of variance. High variability was found in almost all groups. There were statistically significant differences between obese and nonobese individuals in: OSI EC, APSI EC, MLSI EC, and FRI 12-6 parameters. The results of the above analysis are presented in Table 2.

Participants were also divided into two groups according to their age. There were no differences between groups in the test of variance. High variability was found in almost all groups. There were statistically significant differences between older and younger participants in: OSI EO, APSI EO, and FRI 12-6 parameters. The results of the above analysis can be found in Table 3.

Table 2. Differences in the stabilographic parameters between obese and non- obese groups

\begin{tabular}{|l|c|c|c|c|c|c|}
\hline $\begin{array}{c}\text { Stabilographic } \\
\text { parameters }\end{array}$ & $\begin{array}{c}\text { obese } \\
\text { group }\end{array}$ & $\mathrm{CV} \%$ & $\begin{array}{c}\text { non-obese } \\
\text { group }\end{array}$ & $\mathrm{CV} \%$ & $\begin{array}{c}\text { effect } \\
\text { size }\end{array}$ & $p$-value \\
\hline \multicolumn{1}{|c|}{$n$} & 22 & & 34 & & & \\
\hline OSI EO & $0.55 \pm 0.25$ & 45.45 & $0.48 \pm 0.37$ & 77.08 & 0.226 & 0.463 \\
\hline APSI EO & $0.39 \pm 0.23$ & 58.97 & $0.36 \pm 0.20$ & 55.56 & 0.140 & 0.579 \\
\hline MLSI EO & $0.27 \pm 0.14$ & 51.85 & $0.25 \pm 0.32$ & 128.0 & 0.087 & 0.835 \\
\hline OSI EC & $1.51 \pm 0.61$ & 40.40 & $1.13 \pm 0.52$ & 46.02 & 0.673 & $0.016^{*}$ \\
\hline APSI EC & $1.11 \pm 0.50$ & 45.05 & $0.84 \pm 0.41$ & 48.81 & 0.593 & $0.035^{*}$ \\
\hline MLSI EC & $0.79 \pm 0.48$ & 60.76 & $0.53 \pm 0.44$ & 83.02 & 0.565 & $0.041^{*}$ \\
\hline FRI 12-6 & $1.82 \pm 0.72$ & 39.56 & $1.25 \pm 0.57$ & 45.6 & 0.884 & $0.005^{*}$ \\
\hline
\end{tabular}

OSI - Overall Stability Index; APSI - Anterior-Posterior Stability Index; MLSI - Medial-lateral Stability Index; FRI - Fall Risk Index; EO - Eyes Open; EC - Eyes Closed; obese group - participants with a BMI above $30 \mathrm{~kg} / \mathrm{m}^{2}$; non- obese group - participants with a BMI below $30 \mathrm{~kg} / \mathrm{m}^{2}$;

Table 3. Differences in the stabilographic parameters between Older and Younger groups

\begin{tabular}{|l|c|c|c|c|c|c|}
\hline $\begin{array}{c}\text { Stabilographic } \\
\text { parameters }\end{array}$ & $\begin{array}{c}\text { Older } \\
\text { group }\end{array}$ & $\mathrm{CV} \%$ & $\begin{array}{c}\text { Younger } \\
\text { group }\end{array}$ & $\mathrm{CV} \%$ & $\begin{array}{c}\text { Effect } \\
\text { size }\end{array}$ & $p$-value \\
\hline \multicolumn{1}{|c|}{$n$} & 20 & & 36 & & - & - \\
\hline OSI EO & $0.66 \pm 0.42$ & 63.63 & $0.42 \pm 0.22$ & 52.38 & 0.750 & $0.009^{*}$ \\
\hline APSI EO & $0.48 \pm 0.22$ & 45.83 & $0.31 \pm 0.18$ & 58.0 & 0.850 & $0.005^{*}$ \\
\hline MLSI EO & $0.35 \pm 0.39$ & 111.43 & $0.21 \pm 0.14$ & 66.67 & 0.528 & 0.069 \\
\hline OSI EC & $1.29 \pm 0.55$ & 42.64 & $1.28 \pm 0.61$ & 47.66 & 0.017 & 0.903 \\
\hline APSI EC & $0.98 \pm 0.42$ & 42.86 & $0.93 \pm 0.49$ & 53.69 & 0.110 & 0.750 \\
\hline MLSI EC & $0.64 \pm 0.40$ & 62.5 & $0.63 \pm 0.51$ & 80.95 & 0.220 & 0.973 \\
\hline FRI 12-6 & $1.87 \pm 0.85$ & 45.45 & $1.26 \pm 0.49$ & 38.89 & 0.910 & $0.003^{*}$ \\
\hline
\end{tabular}

OSI - Overall Stability Index; APSI - Anterior-Posterior Stability Index; MLSI - Medial-lateral Stability Index; FRI - Fall Risk Index; EO - Eyes Open; EC - Eyes Closed; older group - participants between 60 and 74 years old; younger group - participants between 75 and 90 years old. 
Furthermore, an analysis of variance and post-hoc tests (NIR test) were performed (obesity, age). There were statistically significant differences in OSI EO ( $p=$ $0.027)$, APSI EO $(p=0.034)$, and FRI $12-6(p=$ 0.0002 ) values between obese and non-obese participants in the age groups. The OSI EO parameter showed there was a difference between non-obese young and non-obese old ( $p=0.0043)$ participants. The APSI EO parameter, meanwhile, revealed that there were differences between: non-obese old and non-obese young $(p=0.009)$, and obese old and non-obese young ( $p=0.0402)$ individuals. There was a statistically significant difference in FRI 12-6 values between: non-obese young and non-obese old, nonobese young and obese young, non-obese young and obese old, obese old and non-obese old, obese-old, and obese young subjects. There was no statistical difference between non-obese old and obese young participants. The results of the above analysis are set out in Table 4.
Table 4. Differences in FRI 12-6 parameter between obese and non-obese participants in age groups

\begin{tabular}{|l|c|c|c|c|}
\hline $\begin{array}{c}\text { Participant's } \\
\text { groups }\end{array}$ & $\begin{array}{c}\text { Young } \\
\text { non-obese }\end{array}$ & $\begin{array}{c}\text { Young } \\
\text { obese }\end{array}$ & $\begin{array}{c}\text { old } \\
\text { non-obese }\end{array}$ & $\begin{array}{c}\text { old } \\
\text { obese }\end{array}$ \\
\hline young non-obese & & $0.0110^{*}$ & $0.0099^{*}$ & $0.00005^{*}$ \\
\hline young obese & $0.0110^{*}$ & & 0.86377 & $0.02218^{*}$ \\
\hline old non-obese & $0.0099^{*}$ & 0.86377 & & $0.0355^{*}$ \\
\hline old obese & $0.00005^{*}$ & $0.0222^{*}$ & $0.0355^{*}$ & \\
\hline
\end{tabular}

The ANOVA test for the main effects and factorial designs was performed for static stabilographic parameters in the age groups. There was no significant impact of obesity and non-obesity on the mean values of static stabilographic parameters in the age groups. Age and obesity affect the dependent variable (stabilographic parameters) individually, but there is no interaction effect between these variables. The results are shown in Fig. 1.

Furthermore, the ANOVA test for factorial designs and main effects of the dynamic stabilographic pa-
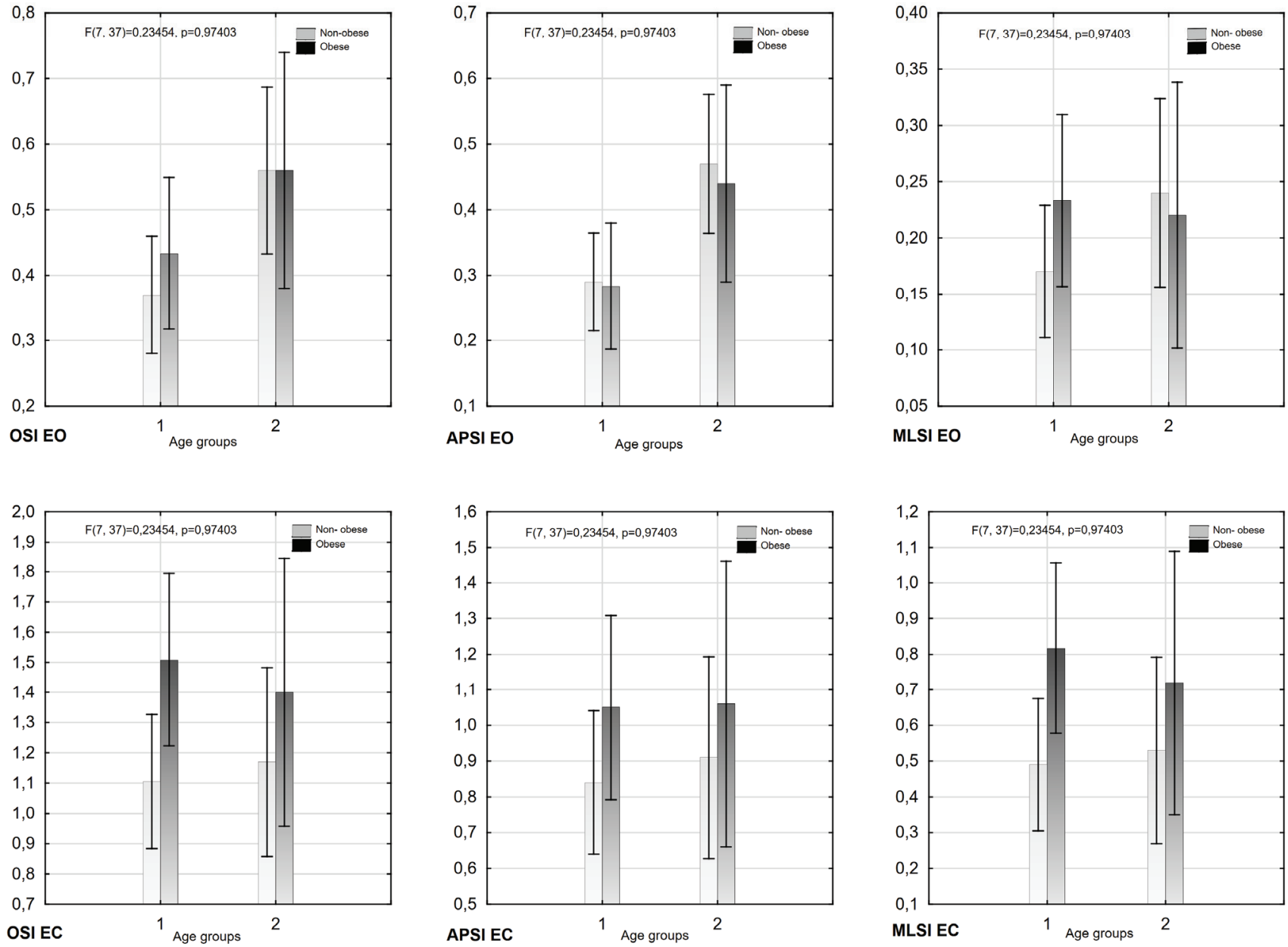

Fig. 1. Differences in static stabilographic parameters between obese and non-obese participants in age groups. OSI - Overall Stability Index, APSI - Anterior-Posterior Stability Index, MLSI - Medial-lateral Stability Index, FRI - Fall Risk Index, EO - Eyes Open, EC - Eyes Closed 


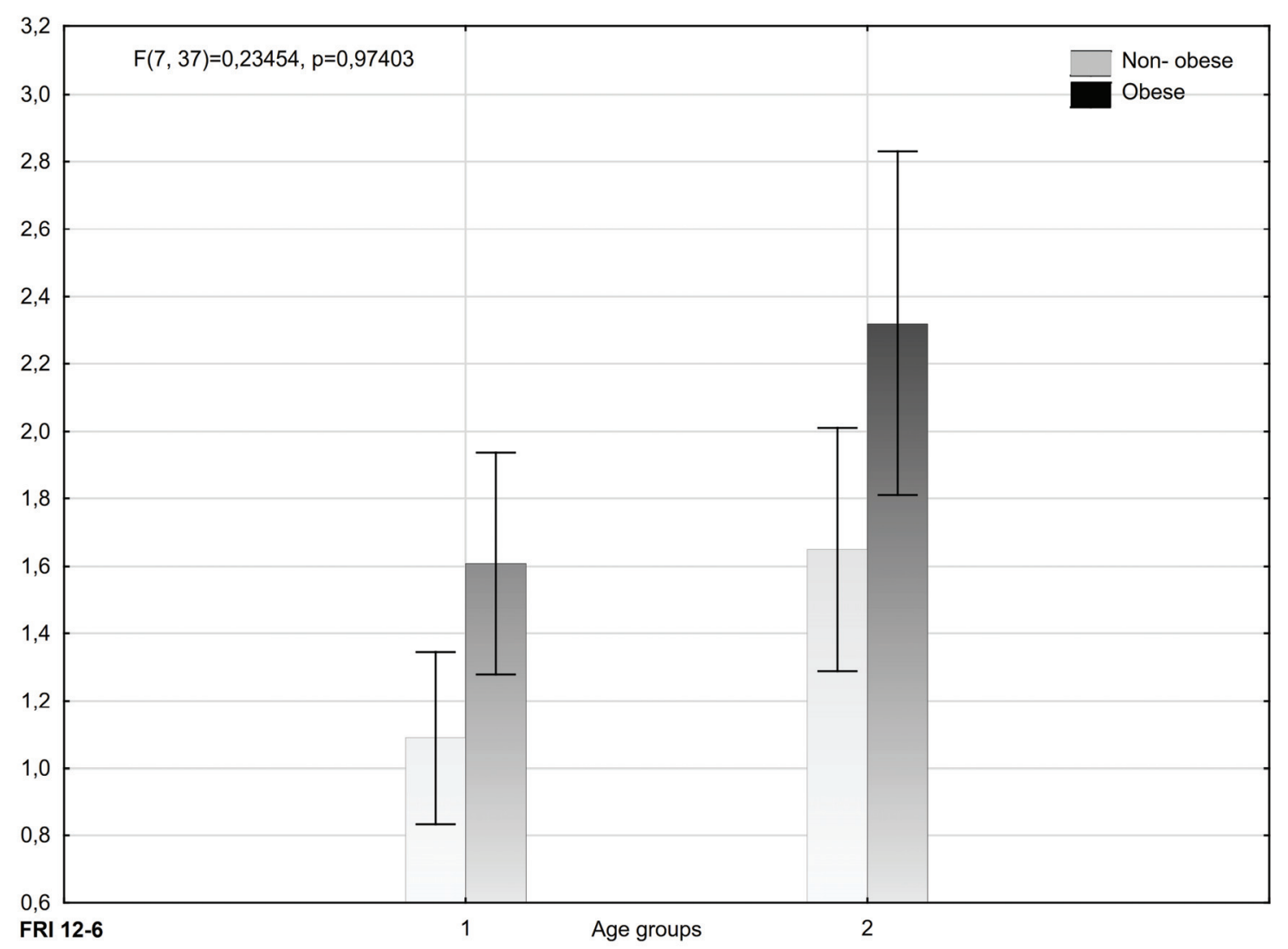

Fig. 2. Differences in FRI 12-6 parameter between obese and non-obese participants in age groups

rameter in age groups was performed. As shown above, age and obesity affect the FRI 12-6 value individually, but there is no interaction effect between these variables. The results of the above analysis are presented in Fig. 2.

\section{Discussion}

Unfortunately, older people tend to weigh more due to various changes in modern society, lower levels of physical activity, and inappropriate eating habits [9], [13]. Moreover, older people have impaired balance control as a result of senility-related processes [10], [11]. Falls result in injury, a heightened fear of falling, and decreased levels of physical activity in the elderly. Around $10 \%$ of falls may result in serious injuries [12]. Moreover, females are more likely to fall than men [11]. Yi et al. [34] checked the sex-specific association between body mass index (BMI) and falls in Korean adults. They concluded that obesity was associated with a greater risk of falls in females, whereas underweight seemed to be associated with a greater risk of falls in males. Numerous studies have shown that there is a relationship between obesity, age and falls. The results of previous studies have shown that high body mass (BMI) has a negative impact on body balance control [5], [14], [18]. This means that obesity reduces the level of physical activity in the elderly [13], [17].

In the above study, there were statistically significant differences in stabilographic parameters in certain age and obese groups in women over 60. It follows, therefore, that obesity and age have an impact on the risk of falls, but they occur with different stabilographic parameters. Age affects FRI 12-6 and static indices with eyes open (OSI EO, APSI EO) and obesity affects FRI 12-6 and static indicators with eyes closed (OSI EC, APSI EC, MLSI EC). Based on the above results, both age and obesity may be the causes of falls.

Lockhart et al. [18] also investigated whether obesity has an influence on the quiet postural stance and gait stability when walking $10 \mathrm{~m}$. Unfortunately, all measurements were performed with eyes open and only changes in linear parameters were presented. They divided participants according to falls history over the previous two years, and they formed fallers and nonfallers groups. Statistically significant differences were noted between fallers and non-fallers, as well as between obese and non-obese participants. They con- 
cluded that BMI is a risk factor for falls in the elderly as measured by gait and postural stability parameters. It is worth mentioning that Himes and Reynolds also proved that obesity appears to be associated with FR among older people. They concluded that being underweight is not related to FR [14]. Ercan et al. [8] showed that obesity is also one of the many risk factors for falls. Interestingly, they conducted research on a group of middle-aged people, which proves that obesity as a risk factor for falling is not necessarily related to age. Moreover, Kejonen et al. [16] compared various anthropometric characteristics with stabilographic parameters which were performed with eyes open and closed. They revealed in their study that obesity is associated with anterior displacement of the centre of mass (COM). This state influences trunk posture and body balance while standing and walking. They also showed differences between the male and female groups in the correlations. Interestingly, age did not lead to any remarkable differences [16]-[18].

On the other hand, Byoung-Jin [5] has suggested that the FR increased for obese people, because postural stability was compromised, thereby limiting movement. He assessed the body balance of the participants, using functional tests with eyes open (Time Up and Go, one-leg standing test). He showed a relationship between age, obesity, and the FR. There was a negative correlation between BMI, gender, and falls efficacy. Moreover, he suggested that a lower BMI leads to a higher risk of severe injury. Actually, this study showed that obesity not only affects the risk of falling but also the consequences of falls. Mitchell et al. [20] also demonstrated a relationship between BMI, age and risk of falls. They also concluded that older obese people have an increased risk of falls. There was no significant association between fall injuries and increasing BMI. Unfortunately, they did not conduct any stabilographic tests, only an interview. Moreover, obese women aged 55 years and older may not be at an overall increased risk of falling, but may experience a greater rate of trip-related falls [24].

Obesity affects indicators with eyes closed and the dynamic stabilographic parameter (FRI 12-6). These results relate to the fact that obese individuals probably have problems mainly with how the proprioceptive system works, because of reduced plantar sensitivity. The continuous pressure of supporting a large mass causes hyperactivation of the plantar mechanoreceptors [10], [15]. Moreover, a greater mechanical demand due to their large body mass causes a greater gravitational torque. This gravitational torque accelerates the body and must be countered by muscular tor- ques [26]. The above studies imply a need to take into account the type of obesity, the distribution of adipose tissue, and the hip and waist circumferences when assessing fall risk in obese individuals [18]. Neri et al. [21] in their study examined the association between gynoid and android obesity in falls risk in women aged 60 and over. This study showed, that gynoid obesity is associated with an increased risk of falls in older women. Gonzalez et al. [10] claimed that increased BMI, in absence of comorbidities or clinically functional impairments, may not influence balance during walking.

It is well known that musculoskeletal conditions are associated with age, obesity, and affect postural stability [17]. Low muscle strength in lower limbs is associated with body balance disorders [17], [28]. It worth mentioning that some obese people, at the same time, may also experience low muscle mass [4], [28]. This state, characterised by high adiposity and low muscle mass and strength, is called sarcopenic obesity (SO). On the other hand, some obese individuals may have increased muscle mass due to maintaining a large body mass [3]. Öztürk et al. [22] have proved that sarcopenically obese individuals have the highest risk of falls.

After considering a two-factor design (age and obesity), there were statistically significant differences between Obese and Non-obese participants in the age groups (OSI EO, APSI EO, FRI 12-6). It is known from experience that the most important of these parameters is FRI 12-6, because fall risk assessment should take place in dynamic environments, not in static ones. Although the statistically significant differences in the NIR test were in almost all age and obesity combinations, there were no statistical differences between non-obese old and obese young groups $(0.863)$. This study shows that nonobese people have better stability because there is a lack of differences between younger and obese people. This shows that obesity has a bad effect on stability, while age depends on other factors as well. If older people are non-obese or fit, involutional changes can be reversed through an active life and a balanced diet. This indicates that both obese young and non-obese old individuals may have body balance disorders due to the presence of one of the risk factors.

In our case, the question was whether there is an interaction between obesity and age in the risk of falling. There is no evidence of any interaction between age and obesity in variable stabilographic parameters. It is worth mentioning that Himes and Reynolds examined the effect of the interaction be- 
tween age, sex, body size and falls risk. They only mentioned these analyses and did not publish their results in their study. As with the above study, none of the interactions were significant [14]. It is well known, that the risk of falls increase with age. Wiśniewska-Szurlej et al. [32] assessed the stability of older women and men receiving institutional care. They concluded that age presented the strongest correlation with an increase in stabilometric parameters. On the other hand, Lee et al. [17] tried to determine whether BMI-based obesity is associated with decreased body balance and whether instability has relationships with the main risk factors for falls. They showed that older people with obesity have poorer balance abilities and it is associated with the decreased strength of the lower limbs. Moreover, they concluded, that BMI-based obesity can be an independent fall risk as well as age.

\section{Conclusions}

The worse results seen for various parameters may be the result of a failure of various elements leading to a reduced adaptive capacity in the balance control system (feedback control, impaired proprioception/vision/vestibular system). There is no doubt that all of these systems deteriorate with age, which increases the risk of falls in the elderly. Obese people also show an increased risk of falling compared to non-obese people. In this case, the type of obesity, and the location of the fat tissue, must be taken into account in falls risk assessment. Moreover, there was no interaction between age and obesity. Age and obesity affect the stabilographic parameters individually, but there is no interaction effect between them. If older people are non-obese or fit, involutional changes could be reversed through an active life and a balanced diet. This indicates that both obese young and non-obese old individuals may have body balance disorders due to the presence of one of the risk factors.

\section{Limitations of the study}

Participants declared that their falls could have had different background reasons. Some are caused by balance disorders, while the others were uncontrollable due to environmental factors. Moreover, participants who did not fall could have shown increased vigilance connected to a fear of falling. Accordingly, the research should be continued on the bigger number of participants.

\section{References}

[1] Aoyama M., Suzuki Y., Onishi J., KuzuYa M., Physical and functional factors in activities of daily living that predict falls in community-dwelling older women, Geriatr. Gerontol. Int., 2011, 11, 348-357, DOI: 10.1111/j.1447-0594.2010.00685.x.

[2] Barazzoni R., Bischoff S., Boirie Y., Busetto L., Cederholm T., Dicker D., Toplak H., Van Gossum A., Yumuk V., VetTorf R., Sarcopenic Obesity: Time to Meet the Challenge, Obes. Facts, 2018, 11 (4), 294-305, DOI: $10.1159 / 000490361$.

[3] Bовошік P., Sarcopenic obesity in older people, Adv. Rehab., 2020, 34 (4), 25-35, DOI: 10.5114/areh.2020.100297.

[4] Bobowik P., Wiszomirska I., Diagnostic dependence of muscle strength measurements and the risk of falls in the elderly, Int. J. Rehabil. Res., 2020, 43 (4), 330-336, DOI: 10.1097/ MRR.0000000000000430.

[5] Byoung-Jin J., The Effects of Obesity on Fall Efficacy in Elderly People, J. Phys. Ther. Sci., 2013, 25 (11), 1485-1489, DOI: $10.1589 /$ jpts.25.1485.

[6] Dutil M., Handrigan G.A., Corbeil P., Cantin V., Simoneau M., Teasdale N., Hue O., The impact of obesity on balance control in community-dwelling older women, Age (Dordr.) 2013, 35 (3), 883-890, DOI: 10.1007/ s11357-012-9386-x.

[7] Dykes P.C., Bogaisky M., Carter E.J., Duckworth M., HuRLeY A.C., JACKSON E.M., KHASNABISH S., LiNDROS M.E., LiPSitZ S.R., SCANLAN M., YU S.P., Bates D.W., AdElman J.S., Development and Validation of a Fall Prevention Knowledge Test, J. Am. Geriatr. Soc., 2019, 67 (1), 133-138, DOI: 10.1111/jgs. 15563 .

[8] ERCAN S., Baskurt Z., Baskurt F., Cetin C., Balance disorder, falling risks and fear of falling in obese individuals: cross-sectional clinical research in Isparta, J. Pak. Med. Assoc., 2020, 70 (1), 17-23, DOI: 10.5455/JPMA.293668.

[9] Fauziana R., Jeyagurunathan A., Abdin E., Vaingankar J., Sagayadevan V., Shafie S., Sambasivam R., Chong S.A., Subramaniam M., Body mass index, waist-hip ratio and risk of chronic medical condition in the elderly population: results from the Well-being of the Singapore Elderly (WiSE) Study, BMC Geriatr., 2016, 18, 16, 125, DOI: 10.1186/ s12877-016-0297-z.

[10] GonZalez M., Gates D.H., Rosenblatt N.J., The impact of obesity on gait stability in older adults, J. Biomech., 2020, 13, 100, 109585, DOI: 10.1016/j.jbiomech.2019.109585.

[11] Gouveia É.R., Gouveia B.R., Ihle A., Kliegel M., MARQues A., FreitAS D.L., Balance and mobility relationships in older adults: A representative population-based cross-sectional study in Madeira, Portugal, Arch. Gerontol. Geriatr., 2019, 80, 65-69, DOI: 10.1016/j.archger. 2018.10.009.

[12] Grant A., Mackenzie L., Clemson L., How do general practitioners engage with allied health practitioners to prevent falls in older people? An exploratory qualitative study, Australas J. Ageing, 2015, 34 (3), 149-54, DOI: 10.1111/ajag.12157.

[13] Hardy R., CoOper R., Aihie Sayer A., Ben- Shlomo Y., Cooper C., Deary I.J., Demakakos P., Gallacher J., Martin R.M., McNeill G., Starr J.M., Steptoe A., Syddall H., Kun D., Body Mass Index, Muscle Strength and Physical Performance in Older Adults from Eight Cohort Studies: The HALCyon Programme, PLoS One, 2013, 8 (2), e56483, DOI: 10.1371/journal.pone.0056483. 
[14] Himes C.L., REYNOLDS S.L., Effect of obesity on falls, injury, and disability, J. Am. Geriatr. Soc., 2012, 60 (1), 124-129, DOI: $10.1111 / \mathrm{j} .1532-5415.2011 .03767 . x$.

[15] Hue O., Simoneau M., Marcotte J., Berrigan F., Doré J., Marceau P., Marceau S., Tremblay A., Teasdale N., Body weight is a strong predictor of postural stability, Gait Posture, 2007, 26, 32-38, DOI: 10.1016/j.gaitpost.2006.07.005.

[16] Kejonen P., Kauranen K., Vanharanta H., The relationship between anthropometric factors and body-balancing movements in postural balance, Arch. Phys. Med. Rehabil., 2003, 84 (1), 17-22, DOI: 10.1053/ apmr.2003.50058.

[17] LeE J.J., Hong D.W., LeE S.A., Soh Y., YANG M., ChOI K.M., Won C.W., CHON J., Relationship Between Obesity and Balance in the Community-Dwelling Elderly Population: A Cross-Sectional Analysis, Am. J. Phys. Med. Rehabil., 2020, 99 (1), 65-70, DOI: 10.1097/PHM.0000000000001292.

[18] Lockhart T.E., Frames C.W., SoAngra R., Lieberman A., Effects of Obesity and Fall Risk on Gait and Posture of Community-Dwelling Older Adults, Int. J. Progn. Health Manag., 2019, 10 (1), 019.

[19] Matter K.C., Sinclair S.A., Hostetler S.G., Xiang H., A comparison of the characteristics of injuries between obese and non-obese inpatients, Obesity (Silver Spring), 2007, 15 (10), 2384-2390, DOI: 10.1038/oby.2007.283.

[20] Mitchell R.J., LoRD S.R., HARVEy L., Close J.C.T., Associations between obesity and overweight and fall risk, health status and quality of life in older people, Aust. N. Z. J. Public Health, 2014, 38 (1), 13-18, DOI: 10.1111/1753-6405.12152.

[21] Neri S.G.R., Tiedemann A., Gadelha A.B., Lima R.M., Body fat distribution in obesity and the association with falls: A cohort study of Brazilian women aged 60 years and over, Maturitas, 2020, 139, 64-68, DOI: 10.1016/j.maturitas. 2020.06.009.

[22] ÖZTÜRK Z.A., TÜRKBEYLER İ.H., ABIYEV A., KUL S., EdIZER B., YAKARYILMAZ F.D., SOYLU G., Health-related quality of life and fall risk associated with age-related body composition changes; sarcopenia, obesity and sarcopenic obesity, Intern. Med. J., 2018, 48 (8), 973-981, DOI: 10.1111/ imj.13935.

[23] Parraca J.A., Olivares P.R., Carbonell-Baeza A., APARICIO V.A., ADSUAR J.C., GUSI N., Test-retest reliability of Biodex Balance SD on physically active old people, J. of Hum. Sport and Exercise, 2011, 6 (2), 444-451, DOI: 10.4100/ jhse.2011.62.25.
[24] Rosenblatt N.J., Grabiner M.D., Relationship between obesity and falls by middle-aged and older women, Arch. Phys. Med. Rehabil., 2012, 93 (4), 718-722, DOI: 10.1016/ j.apmr.2011.08.038.

[25] Sierra-GuZmán R., JimÉnez F., Abián-VicÉn J., Predictors of chronic ankle instability: Analysis of peroneal reaction time, dynamic balance and isokinetic strength, Clin. Biomech., 2018, 54, 28-33, https://doi.org/10.1016/j.clinbiomech.2018.03.001

[26] Simoneau M., Corbeil P., The effect of time to peak ankle torque on balance stability boundary: experimental validation of a biomechanical model, Exp. Brain Res., 2005, 165, 217-228, DOI: 10.1007/s00221-005-2290-1.

[27] Steverson M., Ageing and Health. IOP Publishing World Health Organization https://www.who.int/news-room/factsheets/detail/ageing-and-health. Accessed 10 July 2019.

[28] Tanimoto Y., Watanabe M., Sun W., Sugiura Y., HAYASHIDA I., KUSABIRAKI T., TAMAKI J., Sarcopenia and falls in community-dwelling elderly subjects in Japan: defining sarcopenia according to criteria of the European Working Group on Sarcopenia in older people, Arch. Gerontol. Geriatr., 2014, 59, 295-299, DOI: 10.1016/j.archger.2014.04.016.

[29] WHO: World Health Organization, https://pssegostyn.pis.gov.pl/ plikijednostki/wssegorzow/pssegostyn/userfiles/file/Oswiata/ \%C5\%9ADZ\%20informacja.pdf. Accessed 13 December 2019.

[30] WHO: World Health Organization. Mean Body Mass Index (BMI), https://www.who.int/gho/ncd/risk_factors/bmi_text/en/. Accessed 13 December 2019.

[31] Wilczyński J., Pedrycz A., Mucha D., Ambroży T., Mucha D., Body Posture, Postural Stability, and Metabolic Age in Patients with Parkinson's Disease, Biomed. Res. Int., 2017, 2017, 3975417, DOI: 10.1155/2017/3975417.

[32] WiŚnIOWSKA-SZURLEJ A., ĆWIRLEJ-SOZAŃSKA A.B., WiLMOWSKA-PIETRUSZYŃSKA A., WolosZYN N., SOZAŃSKI B., Gender differences in postural stability in elderly people under institutional care, Acta Bioeng. Biomech., 2019, 21 (2), 46-53, DOI: 10.5277/ABB-01327-2019-01.

[33] WisZOMIRSKA I., KACZMARCZYK K., ZDRODOWSKA A., BŁAŻKIEWICZ M., ILNICKA L., MARCINIAK T., Evaluation of static and dynamic postural stability in young, elderly and with vision loss women, Adv. Rehab., 2013, (3), 33-39, DOI: 10.2478/rehab-2014-0019.

[34] Yi S-W., KIM Y.M., Won Y.J., KIM S.K., KIM S.H., Association between body mass index and the risk of falls: a nationwide population-based study, Osteoporos. Int., 2021, DOI: 10.1007/s00198-020-05725-1. 